\title{
Enhancing students' sense of belonging through school celebrations: A study in Finnish lower-secondary schools
}

\author{
Niemi, Pia-Maria $\square$ \\ Department of Teacher Education, University of Helsinki, Finland (pia-maria.niemi@helsinki.fi) \\ Hotulainen, Risto \\ Department of Teacher Education, University of Helsinki, Finland (risto.hotulainen@helsinki.fi)
}

Received: 23 April 2015

Available Online: 15 June 2015

Revised: 4 May $2015 \quad$ Accepted: 3 June 2015

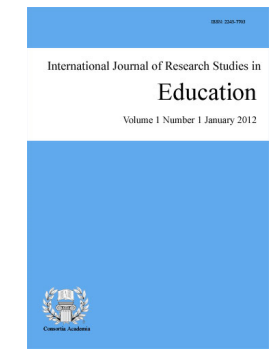

ISSN: 2243-7703 Online ISSN: 2243-7711

OPEN ACCESS

\section{Abstract}

The notion of school belonging refers to the sense of membership and relatedness individual students feel with the other students and with the teachers at their school. Educational and psychological studies carried out in various contexts have shown that students' sense of school belonging is associated with several academic and non-academic outcomes, such as students' motivation to learn, level of academic achievement, and general future orientation. However, one of the major gaps in school belonging studies is the lack of connections between theoretical studies and actual school practice. There is an international need to gain a better understanding of the factors affecting students' sense of belonging in schools. To deepen our knowledge of how schools can better promote students' sense of school belonging at the whole-school level, this study focuses on school celebrations. The study consists of a statistical survey questionnaire conducted at three Finnish lower-secondary schools during the 2013-2014 academic year. To analyze the data and test the methodological hypotheses, we used a structural equation model (SEM). The findings of this study show that students' socio-emotional and educational experiences of school celebrations are positively related to their sense of school belonging. The study also shows the notable role of peer relationships in shaping students' social and emotional experiences of these events. The findings highlight the need for educational researchers, curriculum makers, and practitioners to pay more attention to the social, emotional, and educational content that school celebrations provide for students.

Keywords: school belonging; peer connectedness; school celebrations; co-curricular activities 


\section{Enhancing students' sense of belonging through school celebrations: A study in Finnish lower-secondary schools}

\section{Introduction}

Students' sense of belonging to their school is an internationally topical issue (Allen \& Bowles, 2013; OECD, 2013; Upadyaya \& Salmela-Aro, 2013). The notion of school belonging is based on psychological theories according to which people have an "innate need to belong" (Baumeister \& Leary, 1995). However, one of the major gaps in school belonging studies is the lack of connections between theoretical studies and actual school practices (Allen \& Bowles, 2013). Although many studies have paid attention to the definitions and measurements of students' sense of school belonging, a better understanding of the factors affecting students' sense of belonging in schools is necessary (Allen \& Bowles, 2013; Johnson, 2009; Upadyaya \& Salmela-Aro, 2013). This need has been shown to be internationally relevant. For example, the Programme of International Student Assessment (PISA) 2012 revealed how the overall level of students' sense of belonging decreased in 31 of the 38 countries from which information was collected in 2003, including Finland, the context of our study (OECD, 2013). To deepen our knowledge of how schools can better promote students' sense of school belonging at the whole-school level, this study focuses on school celebrations.

The aim here is to deepen our understanding of the ways school celebrations can contribute to students' sense of school belonging. To achieve this, the study centers on if and how students' socio-emotional experiences and educational outcomes associated with school celebrations are related to their sense of school belonging. In the Finnish context, school celebrations represent one of the most notable forms of co-curricular activities organized for the whole school community (Finnish National Board of Education, 2014a, 2014b, 2004). The study consists of quantitative survey data $(n=696)$ collected from three Finnish lower-secondary schools (students 13-16 years old) in the winter of 2013. Basic education in Finland consists of six years of primary education (grades 1-6) and three years of lower-secondary education (grades 7-9). Based on previous studies, the main assumptions of this study are that school celebrations provide students with socially and emotionally meaningful experiences and cognitive educational experiences. These hypotheses are tested using a structural equation model (SEM) focusing on the relationship between students' experiences of school celebrations and their sense of school belonging. At the end of the paper, we discuss the key findings regarding the value of school celebrations in relation to the outcome variable of belonging.

\section{Theoretical framework for school celebrations and school belonging}

The theoretical framework of this study is based on psychological and educational studies about school belonging and the social, emotional, and educational value of school celebrations. In this study, the sense of belonging is approached as a "psychological sense of membership" (Goodenow, 1993) that is created through all the formal and informal social interactions students experience with their teachers and peers (Ma, 2003; Meeuwisse, Severiens, \& Born, 2010; Cemalcilar, 2010; Rowe \& Stewart, 2009, 2011; Tinto, 1997). To understand the value school celebrations can have in shaping students' experiences of their school, the theory reviews the socio-emotional and educational aspects of school celebrations discussed in previous studies and in the Finnish National Core Curriculum for Basic Education published by the Finnish National Board of Education (hereafter FNBE) (FNBE, 2004, 2014b). As a school is a social community, the role of peers is studied as a central element contributing to both students' sense of belonging and their experiences of joint school celebrations. The theoretical framework forms the basis of the survey instrument and hypothetical model used to investigate the relationship between students' experiences of school celebrations and their sense of school belonging. 


\subsection{School belonging as a sense of membership}

The sense of school belonging refers to the relatedness individuals feel toward the other members of their school community (e.g., Cemalcilar, 2010; Goodenow, 1993). In addition to "sense of school belonging", terms such as "membership" (Goodenow, 1993), "connectedness" (Bond et al., 2007), and "emotional engagement" (Pietarinen, Soini, \& Pyhältö, 2014; Van Ryzin et al., 2009) have been used to describe the core features of the phenomenon. In this study, the sense of school belonging is defined as a "psychological sense of membership" consisting of students' experiences of being included and valued by the other members of the school community (Goodenow, 1993). Students' sense of school belonging is relevant to several academic and non-academic outcomes; a high level of school belonging is positively related with young people's life satisfaction, motivation to learn, level of academic achievement, school conduct, and general future orientation (cf. Bond, 2007; Gillen-O’Neel \& Fuligni, 2013; Crespo, Jose, Kielpikowski, \& Pryor, 2013; Upadyaya \& Salmela-Aro, 2013). Correspondingly, a low sense of belonging has been shown to be associated with an increased risk of dropping out and health problems (Bond et al., 2007; De Witte, Cabus, Thyssen, Groot, \& Maassen van den Brink, 2013; Korhonen, Linnanmäki, \& Aunio, 2013; Langille, Rasic, Kisely, Flowerdew, \& Cobbett, 2012; Lester, Waters, \& Cross, 2013).

Several studies using quantitative, qualitative, and mixed method approaches inform us that students' sense of school belonging from primary to tertiary higher education levels is mainly shaped by relationships with teachers and peers (e.g., Allen \& Bowles, 2013; Cemalcilar, 2010; Goodenow, 1993; Nichols, 2008; Ma, 2003; Sayer, Beaven, Stringer, \& Hermena, 2013; Tillery et al., 2013). One of the most widely used instruments for studying school belonging internationally is the 18-item Psychological Sense of School Membership (PSSM) scale (Goodenow; 1993), which measures students' experiences in terms of their relationships with the students and teachers at their school. The instrument consists of questions such as "I feel proud of belonging to my school", "I am treated with as much respect as other students", and "The teachers here respect me" (Goodenow, 1993). The PSSM has been used by several scholars in the US (e.g., Nichols, 2008) and in other national and language contexts, such as Iran (Babakhani, 2014) and China (Liu \& Lu, 2011). In this study, we use the PSSM scale (Goodenow, 1993) to study the sense of school belonging.

Although the majority of studies on school belonging have been conducted in the US, some recent studies have been conducted in Iran, Australia, Turkey, Peru, the Netherlands, Belgium, Canada, and China (e.g., Babakhani, 2014; Bond et al., 2007; Cemalcilar, 2010; Cueto, Guerrero, Sugimaru, \& Zevallos, 2010; Demanet \& Van Houtte, 2012; Liu \& Lu, 2011; Ma, 2003; Meeuwisse et al., 2010; Rowe \& Stewart, 2009, 2011). In addition, the sense of school belonging has been studied in PISA tests as part of students' engagement (OECD, 2013). These studies highlighted the validity of the phenomenon across international contexts. Regarding the influence of background variables internationally, some studies find gender to be significant (e.g., Ma, 2003; Lam et al., 2012), but others do not (Cemalcilar, 2010; OECD, 2013). Regarding age, studies show that students' sense of belonging often decreases after the transition from primary school to secondary level (e.g., Gillen-O’Neel \& Fuligni, 2013; Lester et al., 2013). However, some scholars question this claim by showing that the negative development is not necessarily continuous or straightforward and that instead much depends on the way schools operate (Gillen-O'Neel \& Fuligni, 2013; Johnson, 2009). In order to see if age, in terms of grade level and gender, has a significant impact in this study, we included these aspects as background questions in the survey.

\subsection{Peer connectedness}

Peer relationships have been found to be a central element shaping students' sense of school belonging and their experiences of school activities (Cemalcilar, 2010; Rowe \& Stewart, 2009, 2011). Studies highlight how influential peer relationships are in shaping young people's sense of school belonging compared to adults or small children (Cemalcilar, 2010; Drolet \& Arcand, 2013). To determine if and how students' experiences of peer relationships affect their sense of school belonging and their experiences of school celebrations, the study 
Niemi, P.-M., \& Hotulainen, R.

includes the "peer connectedness" scale from the "What's Happening in This School" climate inventory (Aldridge \& Ala'l, 2013). Compared to the PSSM instrument where students' experiences of membership are studied based on the ways students feel "appreciated," recognized, and "liked" by other students at their school (see Goodenow, 1993), the "peer connectedness" scale investigates students' experiences of peer relationships in terms of having "contact and friendship between students from diverse cultures and backgrounds" (Aldridge \& Ala'1, 2013, p. 55). The dimension of "peer connectedness" is operationalized by statements such as "I belong to a group of friends" and "Students help me" (Aldridge \& Ala'1, 2013, p. 65). Thus, the statements and questions used in the "peer connectedness" instrument give more insight about the contextual, everyday interactions among peers, while the PSSM scale focuses on viewing peer relationships as part of the students' overall school experience. The different foci of the scales are complementary for investigating if and how students' experiences of peer connectedness are related to their experiences of school celebrations, especially the socio-emotional aspects, and to their sense of belonging.

\subsection{Social and emotional experiences and belonging in school celebrations}

Celebrations are commonly held in schools around the world, including those in Finland. However, as the social and educational roles of celebrations differ from country to country, it needs to be noted that the celebrations investigated in this study refer to whole-school events that are based on the aims and values of the school curriculum. As celebrations are part of schoolwork but differ from curricular activities, such as lessons, they are described here as co-curricular activities (see Westling, Pyhältö, Soini, \& Pietarinen, 2013). Whole-school celebrations are mentioned in the Finnish National Core Curriculum as one of the ways to carry out teaching and learning activities. Traditional celebrations in Finnish schools include, for example, Christmas, Independence Day (6 December), end-of-term "Spring festival," and the Day of the United Nations (FNBE, 2014a). The celebrations investigated in this study are thus aimed at all students and encourage all students to participate and share the social and emotional experiences of the event.

The value of whole-school celebrations in relation to students' sense of school belonging has been previously discussed by Rowe and Stewart $(2009,2011)$. In their intervention studies, the most successful means for enhancing students' sense of school belonging were "positive," "social," and "celebratory" events that were organized "with no financial cost" and attended by all school members (Rowe \& Stewart, 2011, p. 409). The events were organized as part of the school activities and were described as "fun," "relaxed," and "informal" (Rowe \& Stewart, 2011, p. 54). According to Rowe and Stewart, the value of these events was based on the way they provided the different members of the school community with possibilities for reciprocal interaction that differed from the everyday school routine. Another important aspect was the fact that these events were enjoyed by the students and the teachers (Rowe \& Stewart, 2011).

These findings underscore how key features of whole-school celebrations represent a break in the everyday school routine and the extent to which they are perceived to be enjoyable and meaningful by the students (Rowe \& Stewart, 2009, 2011). Another important feature is the way the students' participation in such events increases their sense of inclusion and connectedness with the other members of the school community (Rowe \& Stewart, 2009, 2011). The importance of experiencing connectedness with the school community has also been recognized by school climate studies and studies on inclusive practices (Alridge \& Ala'1, 2013; Roffey, 2013). For example, in the "What's Happening in This School" questionnaire, one of the studied dimensions is the way students "perceive that students at the school are part of a community" (Aldridge \& Ala'1, 2013, p. 55). The previous findings regarding co-curricular events imply that these types of activities are particularly beneficial for providing students with experiences of connectedness and belonging and therefore require further investigation (Pyhältö, Soini, \& Pietarinen, 2010; Rowe \& Stewart, 2009, 2011; Westling et al., 2013).

To discover what kinds of social and emotional experiences students' gain from school celebrations, we investigated students' experiences of a) enjoying school celebrations and b) being included at school celebrations. The aspect of enjoying celebrations covers seeing school celebrations as emotionally positive and 
meaningful events that students like to attend. The second aspect of being included refers to the way students feel that they are being personally and culturally included and respected at school celebrations. While the notion of culture is a liquid concept (Dervin, 2011), it is also one of the main aspects of school celebrations. The practical questions come down to the content of the celebration and the ways the worldviews and other cultural backgrounds of the participants are taken into account. The question of suitable cultural content of school celebrations has been much discussed in Finland and elsewhere in recent years (cf. Hemming, 2011; Poulter, 2013). Based on the previous findings described in this section, we postulate through this study that celebrations need to be experienced both as emotionally enjoyable and socially inclusive for them to bring additional value to students' sense of school belonging. We also theorize that the two dimensions of emotional and social experiences are related. To test these hypotheses, we investigate students' socio-emotional experiences of school celebrations and their connection to students' sense of belonging to their school.

\subsection{Educational outcomes of co-curricular events - Celebrations in Finnish schools}

Studies have shown that co-curricular activities can be particularly beneficial for enhancing the interaction among students and teachers and in provoking positive feelings in students about their school community (e.g., Westling et al., 2013). In addition to the social and emotional aspects, the educational content and learning experiences gained from co-curricular events have been shown to be meaningful for students' wellbeing in the school community. For example, in Westling et al.'s (2013) study, students felt that co-curricular events allowed them to be creative and use their skills in ways they found to be "empowering, joyful, concrete, and useful" (Westling et al., 2013, p. 32). Likewise, the findings of Pyhältö, Soini, and Pietarinen (2010) illuminate how students' learning agency was positively supported by their participation in co-curricular activities, such as school plays. In this study, the focus is on joint celebrations that are mentioned in the Finnish curriculum as particularly important for concretizing the values and cross-curricular themes of education (FNBE, 2004, 2014b).

Of the cross-curricular themes in the Finnish curriculum particularly relevant for school celebrations is the content area of "cultural identity and internationalism." This includes learning about "one's own culture, the culture of one's home region, and the nature of being Finnish, Nordic and European" (FNBE, 2004, p.37). The content area also includes "other cultures and multiculturalism" and "the importance of cultural manners" (FNBE, 2004, p.37). The 2004 curriculum will be replaced with a new version by 2016, but the documents are similar in their discussions regarding the nature of school celebrations. In the new curriculum, school celebrations and other events are seen as important for creating a "sense of community" within schools and for making the "cultural and linguistic diversity" of the school visible (FNBE, 2014b, p. 43). Corresponding to the 2004 version, the new curriculum also regards celebrations as one of the means of enhancing students' "cultural competencies, interaction and expression" (NFBE, 2014b, 101-102). This is specified to mean that students are guided to "appreciate the traditions and habits of their own family and community as well as those of others" and that students are offered opportunities to "familiarize themselves with cultural heritage" and to "gain experiences of internationality" (FNBE, 2014, 102). Celebrations are also used as vehicles for cultural or intercultural understanding, and their content has also been a topic of discussion in the UK (Hemming, 2011) and the US (Hao, 2009; Kromidas, 2011; Whittaker, Salend, \& Elhoweris, 2009), for example.

As these findings show, one of the main educational aims of school celebrations in Finland, as well as in other countries, is to enhance students' intercultural competencies by improving their understanding of different cultural traditions and by making them aware of the significance these elements have in peoples' lives. By highlighting the role of celebrations as a meeting point for cultural diversity, it can also be seen that the Finnish curricula view the events as occasions for enhancing the sense of connectedness and respect among members of the school community. To determine how these aims are met in practice and to discover how they affect students' sense of school belonging, we studied the educational outcomes of school celebrations by focusing on the students' increased knowledge about different cultural and historical traditions and their increased appreciation of different traditions. The aim of the self-evaluation questions was to identify the extent to which students 
Niemi, P.-M., \& Hotulainen, R.

believe they have learned about different traditions and how their appreciation of different traditions has increased as a result of attending school celebrations. The question of if and how the educational outcomes of school celebrations are associated with students' sense of school belonging, either directly or through the other studied dimensions, is relevant for developing the educational content and social significance of these events.

\section{Aims and research questions}

The aim of this study is to investigate if and how students' socio-emotional experiences and educational outcomes of school celebrations are related to their sense of school belonging and how the role of peer connectedness is associated with these dimensions. Based on the theoretical framework, we designed the hypothetical model of the different variables in Figure 1.

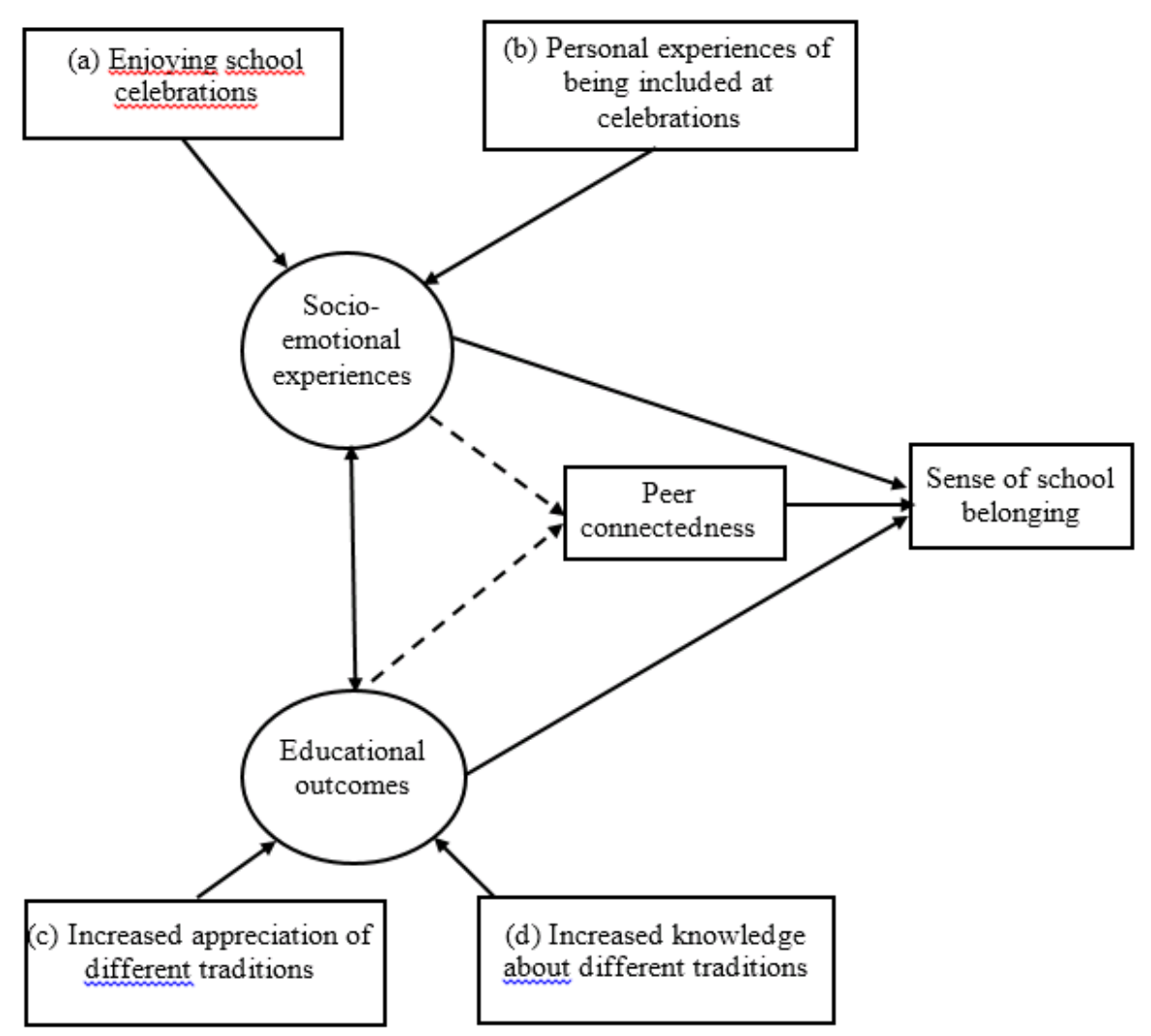

Figure 1. Hypothesized model predicting school belonging.

The outcome variable of the hypothetical model is students' sense of school belonging. The predictor variables used to explain students' sense of belonging are as follows:

Students' socio-emotional experiences of school celebrations consist of:

a) emotional experiences of enjoying school celebrations and

b) social experiences of being included at school celebrations.

The educational outcomes consist of students'

c) increased appreciation of different traditions as a result of participating in school celebrations and

d) increased knowledge about different traditions gained from school celebrations. 
Enhancing students' sense of belonging through school celebrations: A study in Finnish lower-secondary schools

Peer connectedness consists of students' mutual relationships in everyday school life.

\subsection{Research questions}

The main research questions of this study are as follows:

$>$ How are students' socio-emotional experiences and educational outcomes of school celebrations related to their sense of school belonging?

$>\quad$ If relationships exist, how are they influenced by experiences of peer connectedness?

To answer our research questions, we tested four methodological hypotheses vis-à-vis the model:

$>$ H1) Measurement models of the latent variables, here called "socio-emotional experiences" and "educational outcomes", identify along with the hypothesized model (illustrated in Figure 1).

$>$ H2) The latent variables of "socio-emotional experiences" and "educational outcomes" provide additional predictive value, both individually and combined, for "school belonging".

$>\quad$ H3) "Peer connectedness" has a strong effect on school belonging and mediates the effects of both the latent variables "socio-emotional experiences" and "educational outcomes" on "school belonging."

$>$ H4) Measurement models for "socio-emotional experiences" and "educational outcomes" are invariant across schools because the underlying latent factor structures are independent of schools and capture broader perceptions of students in the context of school celebrations.

\section{Method}

The study consists of questionnaire data the first author collected from three lower-secondary schools of basic education during the 2013-2014 academic year. To analyze the data and test the methodological hypotheses, we used a SEM. As the meaning of reference groups is significant during lower secondary years, we chose the sample from among Grade 8 and Grade 9 students. In addition, the population displays a high degree of heterogeneity, meaning celebrations may have a relatively higher degree of meaning for them than for other population groups in the Finnish educational system.

\subsection{Data collection and participants}

The data were gathered from three public lower-secondary schools in southern Finland by the first author as a part of a mixed-method design. Official permissions to conduct the study were obtained from the respective municipalities, headmasters, and guardians. At the time of the data collection, each of the schools had a population of between 300 and 500 students and were mainly attended by students living in the surrounding areas. Prior to the main study reported here, the questionnaire was pre-tested for reliability and validity with a target group of 32 students from a school that did not take part in the actual study. The pilot group answered the questionnaire as well as provided feedback about the questions. Reliability estimates were calculated for all questionnaire items and the ones that did not work well in the pilot test were either re-formulated or eliminated from the final versions of each measure.

The data were gathered from all Grade 8 and Grade 9 students (14-16 years old) at the three schools to obtain a comprehensive sample. The researcher distributed the code-numbered questionnaires to the three schools in November 2013. The headmasters of the schools informed the guardians of all Grade 8 and Grade 9 students about the survey. The teachers were advised to inform the students that the questionnaire was optional and would not affect the students' grades in any way. The questionnaires were answered anonymously to guarantee confidentiality. The time reserved for filling out the questionnaire ranged from approximately 10-20 minutes, depending on the school. The questionnaire included two pages and was completed by the pilot group 
Niemi, P.-M., \& Hotulainen, R.

within 10 minutes. In total, 761 questionnaires were returned, and after removing those with more than 10 missing values, 696 were included in the final analysis. Of the respondents, $52 \%$ were female $(n=363)$ and $47 \%$ were male $(n=326)$; seven people did not identify their gender. The three schools are identified in the data with the letter "S" for "school" and a number (1, 2, or 3).

\subsection{Instruments used}

The study used six scales to capture the key elements under investigation. International tests, such as the PSSM scale and scales from the WHITS questionnaire, were translated into Finnish by the first author, in cooperation with educational research and English language experts. Items with high reliability scores were included in the final analysis model. The following scales were used.

Sense of school belonging was measured using Goodenow's (1993) Psychological Sense of School Membership (PSSM) scale. The scale consists of statements such as "Other students in this school take my opinions seriously" and "The teachers here respect me" (the Cronbach's alpha of the seven valid items was .91).

Peer connectedness was measured using the "peer connectedness" scale from the What's Happening in This School questionnaire (Aldridge \& Ala'1, 2013). The questionnaire was previously tested for reliability and validity by Aldridge and Ala'l (2013). The scale includes items such as "I belong to a group of friends" and "I feel accepted by other students" (Aldridge \& Ala'l, 2013) (the Cronbach's alpha of the seven valid items was .92).

Enjoying school celebrations was measured using a three-item scale that included the items "I think it is important that celebrations are held at school", "I like attending school celebrations," and "School celebrations are nice events" (the Cronbach's alpha of the three valid items was .87). Similar scales have been employed by Ladd and Dinella (2009) to study students' liking and avoidance of their school.

Personal experiences of being included at school celebrations was measured using a modified version of the "school connectedness" scale of the WHITS questionnaire (Aldridge \& Ala'l, 2013). The modified versions of the questions were "I feel included in school celebrations", "I feel that my culture is valued in school celebrations," and "I feel that my culture is respected in school celebrations" (the Cronbach's alpha of the three valid items was .90).

Increased appreciation of different traditions was measured using nine items, such as "School celebrations help me to appreciate Finnish holidays" and "School celebrations help me to appreciate the celebrations we have at home" (the Cronbach's alpha of the eight valid items was .96).

Increased knowledge about different traditions was measured using six items, such as "I have learned much about the history of Finland through school celebrations" and "I have learned much about other countries' holidays through school celebrations" (the Cronbach's alpha of the four valid items was .91). Similar questions have been used by Marks (2000) in his Five-Factor Student Evaluation Model to study students' experiences of "perceived learning".

\subsection{Analysis procedures}

Descriptive statistical analyses were performed on background variables. Bivariate correlational analysis was conducted to assess the relationship between the dependent variables of the study. SEMs were used to test the hypothesized model. The SEMs were considered to have a good fit with the comparative fit index (CFI), and Tucker-Lewis index $(T L I)>.95$ and root mean square error of approximation $(R M S E A)<.08$. To study the stability of the hypothesized measurement models across schools, it was also necessary to check that the latent factors were measurement-invariant. This was tested by constraining factor loadings (weak factorial invariance) and intercepts (strong factorial invariance) of the measurement models to be equal while letting measurement residuals vary freely (Byrne \& Stewart, 2006). Descriptive statistics were calculated using SPSS22, and 
Enhancing students' sense of belonging through school celebrations: A study in Finnish lower-secondary schools statistical SEM was applied in AMOS22.

\section{Results}

The results section consists of the descriptive statistics, correlational analysis, testing of the SEM, and the results of the SEM.

\subsection{Descriptive statistics}

Table 1 summarizes the descriptive values received by each dimension, measured with a seven-point Likert scale where low scores equate to low agreement with the statement and high scores equate to high agreement.

\section{Table 1}

Measures used to study the dimensions related to school celebrations (by grade, gender, and school)

\begin{tabular}{|c|c|c|c|c|c|c|c|c|c|c|c|c|}
\hline \multirow[t]{2}{*}{$\begin{array}{l}\text { Grade, } \\
\text { gender, and } \\
\text { school }\end{array}$} & \multicolumn{2}{|c|}{$\begin{array}{l}\text { Sense of } \\
\text { school } \\
\text { belonging }\end{array}$} & \multicolumn{2}{|c|}{$\begin{array}{c}\text { Peer } \\
\text { connectedness }\end{array}$} & \multicolumn{2}{|c|}{$\begin{array}{l}\text { Enjoying school } \\
\text { celebrations }\end{array}$} & \multicolumn{2}{|c|}{$\begin{array}{l}\text { Experiences of } \\
\text { being included }\end{array}$} & \multicolumn{2}{|c|}{$\begin{array}{l}\text { Increased } \\
\text { appreciation of } \\
\text { different } \\
\text { traditions }\end{array}$} & \multicolumn{2}{|c|}{$\begin{array}{c}\text { Increased } \\
\text { knowledge about } \\
\text { different } \\
\text { traditions }\end{array}$} \\
\hline & $M$ & $S D$ & $M$ & $S D$ & $M$ & $S D$ & $M$ & $S D$ & $M$ & $S D$ & $M$ & $S D$ \\
\hline Grade 8 girls & 4.62 & 1.11 & 5.36 & 1.28 & 5.17 & 1.36 & 4.78 & 1.45 & 4.36 & 1.49 & 3.70 & 1.43 \\
\hline Grade 8 boys & 4.67 & 1.26 & 5.34 & 1.38 & 4.36 & 1.77 & 4.23 & 1.60 & 4.04 & 1.71 & 3.73 & 1.52 \\
\hline $\begin{array}{l}\text { Grade } 8 \text { girls } \\
\text { and boys }\end{array}$ & 4.64 & 1.18 & 5.34 & 1.32 & 4.78 & 1.61 & 4.51 & 1.55 & 4.20 & 1.60 & 3.71 & 1.47 \\
\hline $\begin{array}{l}\text { Grade } 9 \\
\text { girls }\end{array}$ & 4.20 & 1.00 & 5.22 & 1.09 & 4.86 & 1.53 & 4.27 & 1.45 & 3.95 & 1.43 & 3.38 & 1.37 \\
\hline Grade 9 boys & 4.08 & 1.10 & 4.91 & 1.32 & 4.09 & 1.63 & 3.51 & 1.54 & 3.51 & 1.63 & 3.04 & 1.49 \\
\hline $\begin{array}{l}\text { Grade } 9 \text { girls } \\
\text { and boys }\end{array}$ & 4.15 & 1.06 & 5.08 & 1.24 & 4.51 & 1.62 & 5.08 & 1.24 & 3.75 & 1.54 & 3.23 & 1.44 \\
\hline $\begin{array}{l}\text { Girls in all } \\
\text { schools }\end{array}$ & 4.40 & 1.07 & 5.29 & 1.19 & 5.01 & 1.45 & 4.51 & 1.47 & 4.14 & 1.47 & 3.54 & 1.40 \\
\hline $\begin{array}{l}\text { Boys in all } \\
\text { schools }\end{array}$ & 4.36 & 1.21 & 5.11 & 1.36 & 4.22 & 1.70 & 3.86 & 1.61 & 3.76 & 1.69 & 3.36 & 1.54 \\
\hline S1 & 4.25 & 1.12 & 5.11 & 1.15 & 4.38 & 1.64 & 3.74 & 1.56 & 3.73 & 1.59 & 3.35 & 1.50 \\
\hline S2 & 4.67 & 1.16 & 5.50 & 1.39 & 5.17 & 1.44 & 4.61 & 1.59 & 4.29 & 1.68 & 3.73 & 1.60 \\
\hline S3 & 4.39 & 1.15 & 5.13 & 1.31 & 4.78 & 1.48 & 4.19 & 1.54 & 3.99 & 1.51 & 3.42 & 1.38 \\
\hline Total & 4.39 & 1.14 & 5.21 & 1.29 & 4.73 & 1.55 & 4.20 & 1.57 & 3.97 & 1.57 & 3.46 & 1.48 \\
\hline
\end{tabular}

The descriptive statistics show that the highest values in all schools were given to "peer connectedness", followed by "enjoying celebrations" and "experiences of being included" in celebrations. The lowest values in all schools were given to the scales measuring educational outcomes ("increased appreciation of different traditions" and "increased knowledge about different traditions"). Regarding the background variable of gender, the descriptive statistics show that girls had higher values than boys in most of the measured areas. These differences were further evidenced by the t-test analysis with Bonferroni corrections (alpha $p<.008$ ), which showed that boys had statistically significantly $(p<.001)$ lower values in all the scales, except for "sense of school belonging" and "increased appreciation of different traditions." The results also show that Grade 9 students had statistically significantly $(p<.001)$ lower values in all scales than Grade 8 students. Overall, students" "sense of school belonging" is above the median in all three schools, but the means of S2 $(M=4.67)$ and S1 $(M=4.25)$ are further apart from each other than from S3 $(M=4.39)$. Skewness and the kurtosis of the 
Niemi, P.-M., \& Hotulainen, R.

variables were moderate (between -1 and 1 ) and acceptable.

\subsection{Correlational analyses}

Table 2 shows the intercorrelation matrix for the dependent variables involved in this study. All correlations between the variables are positive and significant. The relationships between school belonging and all other variables are strong, especially for "experiences of being included in celebrations" (.48-.58). It is noteworthy that the lowest correlations emerged between "increased appreciation of traditions" and "peer connectedness" (.30) and "increased knowledge about different traditions" and "peer connectedness" (.24). However, the fact that both these variables measuring educational outcomes correlated more strongly with school belonging implies that both of the measures "peer connectedness" and "sense of school belonging" have their own specific content and function.

Table 2

Intercorrelation matrix for the variables in the study

\begin{tabular}{|c|c|c|c|c|c|c|}
\hline Variable & 1 & 2 & 3 & 4 & 5 & 6 \\
\hline $\begin{array}{l}\text { Sense of school } \\
\text { belonging }\end{array}$ & - & & & & & \\
\hline Peer connectedness & $.642^{* *}$ & - & & & & \\
\hline $\begin{array}{l}\text { Enjoying school } \\
\text { celebrations }\end{array}$ & $.404^{* * *}$ & $.391^{* *}$ & - & & & \\
\hline $\begin{array}{l}\text { Experiences of being } \\
\text { included }\end{array}$ & $.577^{* *}$ & $.484^{* *}$ & $.558^{* *}$ & - & & \\
\hline $\begin{array}{l}\text { Increased appreciation of } \\
\text { different traditions }\end{array}$ & $.437^{* * *}$ & $.296^{* *}$ & $.550^{* *}$ & $.561^{* * *}$ & - & \\
\hline $\begin{array}{l}\text { Increased knowledge } \\
\text { about different traditions }\end{array}$ & $.410^{* *}$ & $.242^{* *}$ & $.371^{* *}$ & $.438^{* *}$ & $.618^{* *}$ & - \\
\hline
\end{tabular}

\subsection{Testing the SEM}

To study the first three methodological hypotheses, a SEM was built and tested. First, the measurement models of latent variables were specified. According to the hypothesized model, these were a) "socio-emotional experiences" (two items: "enjoying school celebrations" and "personal experiences of being included in celebrations" with factor loadings of .94 and .76 and b) "educational outcomes" (two items: "increased appreciation of different traditions" and "increased knowledge about different traditions" with factor loadings of .77 and .88). Knowing that both gender and grade level had effects on the data, these variables were used as manifest moderators. The original model (depicted in Figure 1) did not work properly $(C F I=.886, T L I=.684$, Akaike Information Criterion [AIC] $=330.751, R M S E A=.168 ; \chi^{2}=268.75, d f=18, p<.001$ However, when adding a path from "socio-emotional experiences" to "peer connectedness" (a modified model), the direct effect of "peer connectedness" $(\beta=.56, p<.001)$ on "school belonging" decreased to $\beta=.48$, and the $R^{2}$ of the whole model increased from $51 \%$ to $60 \%$. These changes can be interpreted as a sign of mediation. Furthermore, this change improved the model indices remarkably from the original model (modified model indices: $C F I=.983$, $\left.T L I=.950, A I C=113.629, R M S E A=.066 ; \chi^{2}=49.629, d f=12, p<.001\right)$. ). A path from "educational outcomes" to "peer connectedness" was non-significant and was therefore deleted from the model. The modified model and the statistically significant paths of the modified version for the whole sample $(n=696)$ are presented in Figure 2. 


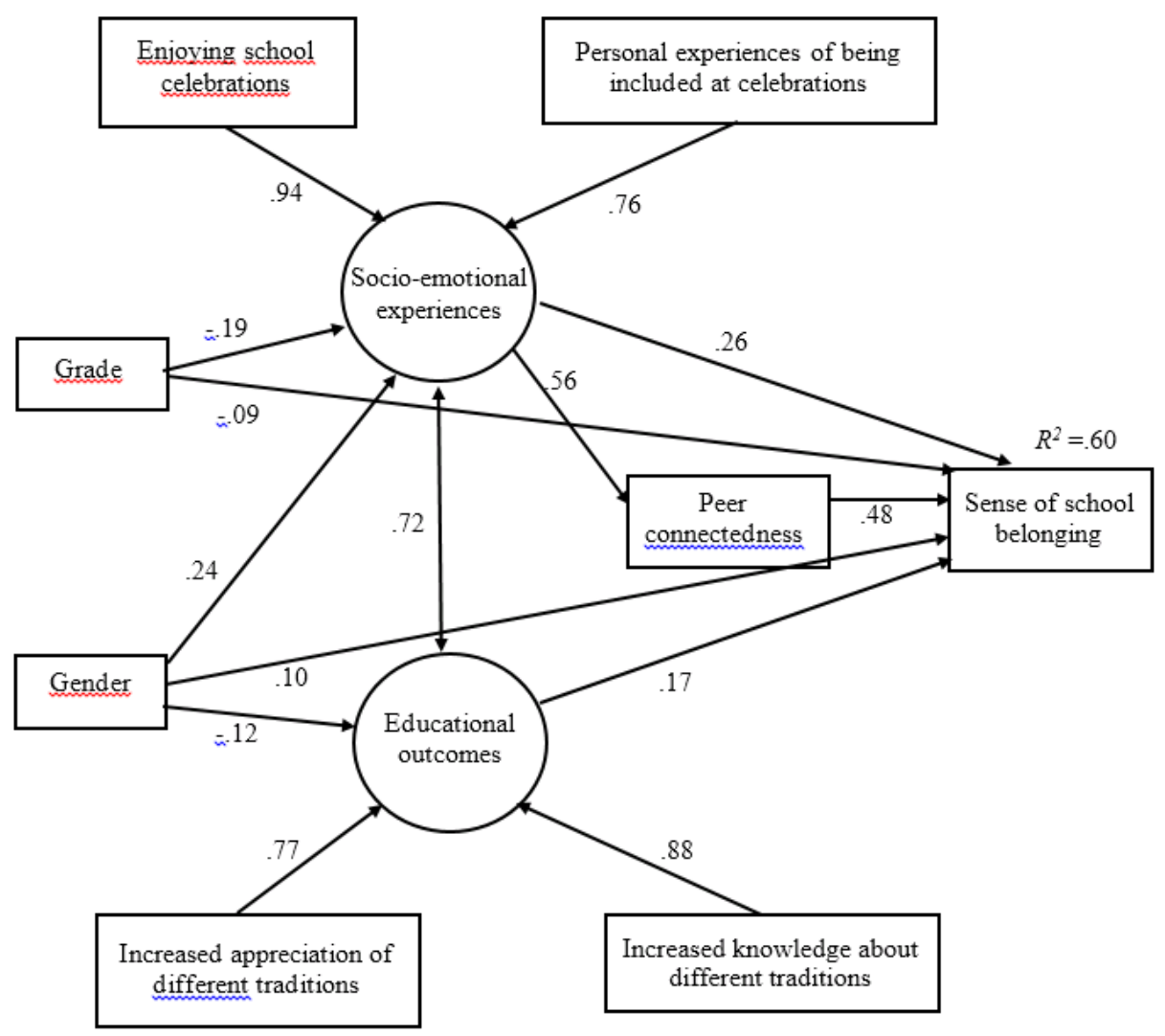

Figure 2. Structural equation model for testing the first of three hypotheses in the study. The standardized

$\beta$-coefficients in the figure are for the whole sample.

\subsection{Results of the SEM}

The results confirm the first three hypotheses related to the model by showing that the latent variables of "socio-emotional experiences" and "educational outcomes" identify along with our hypothesized model. Figure 2 shows that the formed latent variables, "social value of celebrations" $(\beta=.26, p<.001)$ and "learning outcomes," $(\beta=.17, p<.001)$ have direct effects on "sense of school belonging." "Social-emotional experiences" directly explains $7 \%$ of the variance in the sense of "school belonging" and "educational outcomes" directly explains 3\%. However, when taking into account the indirect effects, "socio-emotional experiences" is shown to have an additional effect via "peer connectedness" $(\beta=.27, p<.001)$. This confirms the third methodological hypothesis about the mediating role of "peer connectedness". It is notable that "socio-emotional experiences" has a relatively strong effect $(\beta=.56, p<.001)$ on "peer connectedness". The effects of gender $(\beta$ $=.10, p<.05)$ and grade level $(\beta=-.09, p<.05)$ are weak but statistically significant, as both are shown to explain approximately $1 \%$ of the variance in "sense of school belonging." Altogether, the analysis shows that in the whole sample, "sense of school belonging" is mainly predicted by "peer connectedness" $(\beta=.48, p<.001)$, which explains $23 \%$ of the variance in "school belonging."

For the fourth hypothesis, the measurement invariance across the three schools was tested by stepwise constraining the factor loadings and intercepts to be equal. 
Niemi, P.-M., \& Hotulainen, R.

Table 3

Measurement invariance of three groups

\begin{tabular}{lcccccc}
\hline \multicolumn{1}{c}{ Model } & $\chi^{2}$ & $d f$ & CFI & TLI & RMSEA & $p$ \\
\hline Configural model & 74.707 & 36 & .983 & .948 & .039 & $<.001$ \\
Factor loadings constrained equal & 75.824 & 38 & .983 & .952 & .038 & $<.001$ \\
Measurement intercepts constrained equal & 83.962 & 44 & .982 & .956 & .036 & $<.001$ \\
\hline
\end{tabular}

As the invariance of the factor loadings in Table 2 show, the three groups have the same unit of measurement. Furthermore, the measurement invariance reveals that the scores from the three schools have the same origin. Thus, three findings are indicated: the two latent variables of "socio-emotional experiences" and "educational outcomes" have positive effects on "sense of school belonging", and the significance of "socio-emotional experiences" is mediated by "peer connectedness". These findings are independent of schools.

\section{Discussion and Conclusions}

The aim of this study was to deepen the understanding of students' sense of school belonging. Based on the previous studies by Pyhältö et al., (2010), Rowe and Stewart (2009, 2011), and Westling et al. (2013), all of which highlighted co-curricular activities as beneficial means for enhancing students' sense of school belonging, this study focused on investigating the role of school celebrations. Based on these previous studies and the guidelines given by the FNBE (2004, 2014b), the study hypothesized that school celebrations can be positively related to students' sense of school belonging. To test the methodological hypotheses, the study analyzed the connections between students' socio-emotional experiences and the educational outcomes associated with school celebrations, their sense of peer connectedness, and their sense of school belonging. We begin our discussion with the results of the descriptive statistics, followed by a discussion of the findings and implications of the SEM.

The first notable finding of this study was the fact that Grade 9 students had statistically significantly lower responses than Grade 8 students in all the measured dimensions. This follows the findings of previous studies showing that students' sense of school belonging decreases over the school years (Johnson, 2009). The findings are also consistent with the findings of the latest PISA study about the low sense of school belonging of Finnish Grade 9 students (OECD, 2013). However, extending from these, this study also shows that the decrease does not concern only students' overall sense of belonging but also their sense of peer connectedness and experiences regarding school celebrations. The fact that students' socio-emotional experiences and educational outcomes related to school celebrations decrease in Grade 9 compared to the previous year reveals an important point regarding the ways these events are created and carried out within a school.

Contrary to the findings of PISA 2012 (OECD, 2013) and Cemalcilar's study (2010), gender was not found to be a statically significant background variable for students' sense of school belonging in this study. However, apart from "sense of school belonging" and "increased appreciation for traditions," boys were shown to have statistically significantly lower scores in all the studied areas. This means that boys were found to have less positive socio-emotional experiences of school celebrations than girls, and they also reported gaining less knowledge about different traditions than girls. A similar gap between girls' and boys' experiences has not been identified in previous qualitative studies on co-curricular events carried out in Finland by Pyhältö et al. (2010) or Westling et al. (2013). To determine the reasons behind these notable differences between girls' and boys' and Grade 8 and Grade 9 students' experiences, further investigations are needed. As school celebrations and other co-curricular activities have been studied very little, more studies are needed to determine if these findings are specifically related to these schools, to the content of school celebrations, or to the overall way of conducting whole-school activities. 
However, although the background factors of gender and grade level had an impact on the studied dimensions, together they explained only $2 \%$ of the variation in students' sense of school belonging. This brings us to the results of the SEM that provided a more detailed understanding of the explanation value of the measured dimensions. The statistical analyses of the SEM showed that both the latent variables of "socio-emotional experiences" and "educational outcomes" were positively related with students' sense of school belonging and that they explained more of the variation in students' sense of school belonging than gender and grade level combined. In relation to our first research question ("How are students' socio-emotional experiences and educational outcomes of school celebrations related to their sense of school belonging?") the findings show that students' experiences of school celebrations are positively related with their sense of school belonging and that the experiences related to celebrations had both direct and indirect effects to students' sense of belonging. These findings broaden the understanding of the social and emotional significance of co-curricular experiences gained previously from the studies by Rowe and Stewart $(2009,2011)$, Westling et al. (2013), and Pyhältö et al. (2010).

That students' educational outcomes had only a small effect on their sense of school belonging raises questions about how the events meet the aims of the Finnish curriculum (FNBE, 2004, 2014b). However, it needs to be noted that the educational outcomes measured focused on learning about traditions and that there also exists many other possibilities for studying students' learning in celebrations. Nonetheless, the fact that there was a strong correlation between the students' "educational outcomes" and their "socio-emotional experiences" shows that the educational content of celebrations is also an important element to take into account when evaluating the overall value of these events for students' sense of belonging.

In relation to our second research question ("If relationships exist, how are they influenced by experiences of peer connectedness?"), the findings were notable in showing how the role of peer connectedness mediates the effects between students' "socio-emotional experiences" and "sense of school belonging". The findings elaborate Rowe and Stewart's $(2009,2011)$ findings on celebratory school events as occasions for enhancing peer relationships. The study thus expands previous findings about the value peer relationships have in shaping students' sense of school belonging (Cemalcilar, 2010; Ma, 2003) and that the role of peers is remarkable in specific forms of educational activities, such as school celebrations. Furthermore, invariance testing provided additional convincing evidence of the stability of the hypothesized measurement model across the schools.

The main findings of this study contribute to the existing knowledge base by providing new information about the effects of school celebrations on students' sense of belonging and by presenting an important novel approach to the investigations. While the model used in the study is useful in explaining how school celebrations can contribute to school belongingness, there are also some weaknesses related to it. First, the level of respondents' conscientiousness when filling out the form is an issue that may explain some of the differences between gender and grade level. Therefore, even though this study has shown a promising opening to operationalize a studied conceptual framework and to study it statistically, additional studies are needed to further validate the model by including more accurate questions for each dimension, test the validity of the causal structure, and test the invariance of the model with larger sample sizes from different age groups and school contexts. Furthermore, it should be noted that the SEM is a correlational method, and the influences presented cannot be interpreted as signs of direct causality. For this reason, future research would also benefit from longitudinal research designs in which school celebrations and other co-curricular activities would be studied in various school contexts.

In addition, through such a quantitative approach, we can capture only a narrow picture about celebrations' contextual and cultural features. To achieve a better understanding of the personal and school-level value of school celebrations, the use of mixed methods is necessary. Interviews that probe the meaning structures of students would prove useful for a true triangulation of findings. For this reason, the first author also collected interview data about students' experiences and will report it later on. Taking into account the diversity of school contexts in the world, a particularly important area for future studies is the conducting of comparative studies 
Niemi, P.-M., \& Hotulainen, R.

that include data from different types of schools in various countries and residential areas. However, even though school celebrations may have different meanings in different educational systems, they do occur in schools all over the world. Accordingly, educational research should pay more attention to their specifics, including the social, emotional, and educational significance for students.

\section{Conclusions}

This study shows that whole-school celebrations are positively related to students' sense of school belonging and that peer relationships are important in shaping students' experiences of these events. The findings show that students gain positive social and emotional experiences from these events and that this contributes to their sense of school belonging. Regarding the remarkable mediating role of peer connectedness, the study highlights the need for schools to recognize the role peer relationships play in whole-school activities. From the perspective of educational learning outcomes, it is important that celebrations also strengthen the cognitive aims of the curriculum and provide a successful learning environment with a sense on joy and social participation. The findings of this study also encourage educational researchers, curriculum makers, and practitioners to seek new ways of carrying out celebrations that make them even more emotionally and socially enjoyable for all students and to pay more attention to the social, emotional, and educational experiences students gain from school celebrations. When taking into account the mediating role of peer connectedness, the study reveals that school celebrations are an important way of enhancing students' sense of belonging to their school.

Acknowledgments. We thank Professor Paul Ilsley and Mari-Pauliina Vainikainen, PhD, for their valuable comments on this paper. The first author also expresses her gratitude to Ella and Georg Ehrnrooth's Foundation for the research grant that has funded this study.

\section{References}

Aldridge, J., \& Ala'1, K. (2013). Assessing students' views of school climate: Developing and validating the What's Happening in This School? (WHITS) questionnaire. Improving Schools, 16(1), 47-66. http://dx.doi.org/10.1177/1365480212473680

Allen, K., \& Bowles, T. (2013). Belonging as a guiding principle in the education of adolescents. Australian Journal of Educational \& Developmental Psychology, 12, 108-119.

Babakhani, N. (2014). Perception of class and sense of school belonging and self-regulated learning: A causal model. Procedia - Social and Behavioral Sciences, 116, 1477-1482. http://dx.doi.org/10.1016/j.sbspro.2014.01.420

Baumeister, R., \& Leary, M. (1995). The need to belong: Desire for interpersonal attachments as fundamental human motivation. Psychological Bulletin, 117(3), 497-529. http://dx.doi.org/10.1037/0033-2909.117.3.497

Bond, L., Butler, H., Lyndal, T., Carlin, J., Glover, S., Bowes, G., \& Patton, G. (2007). Social and school connectedness in early secondary school as predictors of late teenage substance use, mental health, and academic outcomes. Journal of Adolescent Health, 40, 357-357. http://dx.doi.org/10.1016/j.jadohealth.2006.10.013

Byrne, B. M., \& Stewart, S. M. (2006). The MACS approach to testing for multigroup invariance of a second-order structure: A walk through the process. Structural Equation Modeling: A Multidisciplinary Journal, 13(2), 287-321. http://dx.doi.org/10.1207/s15328007sem1302_7

Cemalcilar, Z. (2010). Schools as socialisation contexts: Understanding the impact of school climate factors on students' sense of school belonging. Applied Psychology: An International Review, 59(2), 243-272. http://dx.doi.org/10.1111/j.1464-0597.2009.00389.x

Crespo, C., Jose, P., Kielpikowski, M., \& Pryor, J. (2013). “On solid ground”: Family and school connectedness promotes adolescents' future orientation. Journal of Adolescence, 36, 993-1002. 
Enhancing students' sense of belonging through school celebrations: A study in Finnish lower-secondary schools http://dx.doi.org/10.1016/j.adolescence.2013.08.004

Cueto, S., Guerrero, G., Sugimaru, C., \& Zevallos, A. (2010). Sense of belonging and transition to high schools in Peru. International Journal of Educational Development, 30(3), 277-287. http://dx.doi.org/10.1016/j.ijedudev.2009.02.002

Demanet, J., \& Van Houtte, M. (2012). School belonging and school misconduct: The differing role of teacher and peer attachment. Journal of Youth and Adolescence, 41(4), 499-514. http://dx.doi.org/10.1007/s10964-011-9674-2

Dervin, Fred. (2011). A plea for change in research on intercultural discourses. A 'liquid' approach to the study of the acculturation of Chinese students. Journal of Multicultural Discourses, 6(1), 37-52. http://dx.doi.org/10.1080/17447143.2010.532218

De Witte, K., Cabus, S., Thyssen, G., Groot, W., \& Maassen van den Brink, H. (2013). A critical review of the literature on school dropout. Educational Research Review, 10, 13-28. http://dx.doi.org/10.1016/j.edurev.2013.05.002

Drolet, M., \& Arcand, I. (2013). Positive development, sense of belonging, and support of peers among early adolescents: Perspectives of different actors. International Education Studies, 6(4), 29-38. http://dx.doi.org/10.5539/ies.v6n4p29

Finnish National Board of Education. (2014a). Guideline 16.9.2014. The teaching of religious education and secular ethics education and the organization of religious events in early childhood education and in basic education [Ohje 16.9.2014. Uskonnon ja elämänkatsomustiedon opetuksen sekä uskonnollisten tilaisuuksien järjestäminen esi-ja perusopetuksessa]. Retrieved from http://www.oph.fi/download/160301_ohje_uskonnon_ja_elamankatsomustiedon_opetuksen_jarjestamis esta_esi-ja_peru.pdf

Finnish National Board of Education. (2014b). National core curriculum for basic education 2014 [Perusopetuksen opetussuunnitelman perusteet 2014]. Retrieved from http://www.oph.fi/ops2016/perusteet

Finnish National Board of Education. (2004). National core curriculum for basic education 2004 [Perusopetuksen opetussuunnitelman perusteet 2004]. Retrieved from http://www.oph.fi/download/47671_core_curricula_basic_education_1.pdf

Gillen-O'Neel, C., \& Fuligni, A. (2013). A longitudinal study of school belonging and academic motivation across high school. Child Development, 84(2), 678-692. http://dx.doi.org/10.1111/j.1467-8624.2012.01862.x

Goodenow, C. (1993). The psychological sense of school membership among adolescents. Scale development and educational correlates. Psychology in the Schools, 30, 79-90. http://dx.doi.org/10.1002/1520-6807(199301)30:1<79::AID-PITS2310300113>3.0.CO;2-X

Hao, R., N. (2009). Finding spirituality through confrontation and celebration of Asianness in the classroom. In K. G. Hendrix \& J. D. Hamlet (Eds.), As the spirit moves us: New directions for teaching and learning, number 120 (pp. 47-54). http://dx.doi.org/10.1002/tl.376

Hemming, P. J. (2011). Educating for religious citizenship: Multiculturalism and national identity in an English multi-faith primary school. Transactions of the Institute of British Geographers, 36(3), 441-454. http://dx.doi.org/10.1111/j.1475-5661.2011.00432.x

Johnson, L. (2009). School contexts and student belonging: A mixed methods study of an innovative high school. The School Community Journal, 19(1), 99-118.

Korhonen, J., Linnanmäki, K., \& Aunio, P. (2014). Learning difficulties, academic well-being and educational dropout: A person-centred approach. Learning and Individual Differences, 31, 1-10. http://dx.doi.org/10.1016/j.lindif.2013.12.011

Kromidas, Maria. 2011. Troubling tolerance and essentialism. The critical cosmopolitanism of New York City schoolchildren. In F. Dervin, A. Gajardo, and A. Lavanchy (Eds.), Politics of interculturality (pp. 73-98). Newcastle upon Tyne: Cambridge Scholars.

Ladd, G. W. \& Dinella, L. M. (2009). Continuity and change in early school engagement: Predictive of children's achievement trajectories from first to eighth grade? Journal of Educational Psychology, 101(1), 
Niemi, P.-M., \& Hotulainen, R.

190-206. http://dx.doi.org/10.1037/a0013153

Langille, D., Rasic, D., Kisely, S., Flowerdew, G., \& Cobbett, S. (2012). Protective associations of school connectedness with risk of depression in Nova Scotia adolescents. The Canadian Journal of Psychiatry, 57(12), 759-764.

Lam, S., Jimerson, S., Kikas, E., Cefai, C., Veiga, F., Nelson, B., ... Zollneritsch, J. (2012). Do girls and boys perceive themselves as equally engaged in school? The results of an international study from 12 countries. Journal of School Psychology, 50, 77-94. http://dx.doi.org/10.1016/j.jsp.2011.07.004

Lester, L., Waters, S., \& Cross, D. (2013). The relationship between school connectedness and mental health during the transition to secondary school: A path analysis. Australian Journal of Guidance and Counselling, 23(2), 157-171. http://dx.doi.org/10.1017/jgc.2013.20

Liu, Y., \& Lu, Z. (2011). Trajectories of Chinese students' sense of school belonging and academic achievement over the high school transition period. Learning and Individual Differences, 21(2), 187-190. http://dx.doi.org/10.1016/j.lindif.2010.12.007

Ma, X. (2003). Sense of belonging to school: Can schools make a difference? The Journal of Educational Research, 96(6), 340-349. http://dx.doi.org/10.1080/00220670309596617

Marks, R. B. (2000). Determinants of student evaluations of global measures of instructor and course value. Journal of Marketing Education, 22(2), 108-119. http://dx.doi.org/10.1177/0273475300222005

Meeuwisse, M., Severiens, S., E., \& Born, M. Ph. (2010). Learning environment, interaction, sense of belonging and study success in ethnically diverse student groups. Research in Higher Education, 51, 528-545. http://dx.doi.org/10.1007/s11162-010-9168-1

Nichols, S. (2008). An exploration of students' belongingness beliefs in one middle school. The Journal of Experimental Education, 76(2), 145-169. http://dx.doi.org/10.3200/JEXE.76.2.145-169

OECD. (2013). Engagement with and at school. In PISA 2012 results: Ready to learn: Students'engagement, drive and self-beliefs (Vol. III, pp. 39-62). PISA: OECD Publishing.

Poulter, Saila. (2013). Religion in the public space [Uskonto julkisessa tilassa]. Kasvatus 44(2), 162-176.

Pyhältö, K., Soini, T., \& Pietarinen, J. (2010). Pupils' pedagogical well-being in comprehensive school-Significant positive and negative school experiences of Finnish ninth graders. European Journal of Psychology of Education, 25, 207-221. http://dx.doi.org/10.1007/s10212-010-0013-x

Roffey, S. (2013). Inclusive and exclusive belonging - The impact on individual and community well-being. Educational \& Child Psychology, 30(1), 38-49.

Rowe, F., \& Stewart, D. (2011). Promoting connectedness through whole-school approaches: Key elements and pathways of influence. Health Education, 111(1), 49-65. http://dx.doi.org/10.1108/09654281111094973

Rowe, F., \& Stewart, D. (2009). Promoting connectedness through whole school approaches: A qualitative study. Health Education, 109(5), 396-413. http://dx.doi.org/10.1108/09654280910984816

Sayer, E., Beaven, A., Stringer, P., \& Hermena, E. (2013). Investigating sense of community in primary schools. Educational \& Child Psychology, 30(1), 9-25.

Tillery, A., Varjasa, K., Roachb, A., Kuperminc, G., \& Mayers, Joel. (2013). The importance of adult connections in adolescents' sense of school belonging: Implications for schools and practitioners. Journal of School Violence, 12, 134-155. http://dx.doi.org/10.1080/15388220.2012.762518

Tinto, V. (1997). Classrooms as communities. Exploring the educational character of student persistence. Journal of Higher Education, 68(6), 599-623. http://dx.doi.org/10.2307/2959965

Upadyaya, K., \& Salmela-Aro, K. (2013). Development of school engagement in association with academic success and well-being in varying social contexts. A review of empirical research. European Psychologist, 18(2), 136-147. http://dx.doi.org/10.1027/1016-9040/a000143

Westling, S. K., Pyhältö, K., Pietarinen, J., \& Soini, T. (2013). How do ninth-graders perceive their involvement in the most meaningful episodes of their school career? International Journal of Educational Research, 58, 25-35. http://dx.doi.org/10.1016/j.ijer.2012.12.005

Whittaker, C. R., Salend, S., \& Elhoweris, H. (2009). Religious diversity in schools addressing the issues. Intervention in School and Clinic, 44(5), 314-319. http://dx.doi.org/10.1177/1053451208330892 